\title{
Paper
}

\section{Study into Relationship between Uchida-Kraepelin Psychodiagnostic Test Results and Number of Blinks}

\author{
Shunsuke NAKAnO** Non-member, $\quad$ Yolchi KageYama ${ }^{\dagger *}$ Member
}

(Received January 9, 2020, revised July 6, 2020)

\begin{abstract}
Data generated by automatically and quantitatively evaluating subjects' mental and physical conditions can contribute to the improvement of quality of life. The Uchida-Kraepelin psychodiagnostic test not only estimates the individuality of a person but also reflects their mental and physical conditions. To associate the results of this test with objective data, the relationship between the number of blinks and the number of calculations a subject was able to perform in a specific time period was investigated. Analysis of the experimental results indicated that: (a) there was a negative correlation between the number of calculations and number of blinks; (b) the "late increase rate" indicated by the Uchida-Kraepelin psychodiagnostic test was also reflected in the test medium of using a personal computer (PC); (c) there was a significant difference in the number of blinks recorded between the first and second testing periods; and (d) excluding outliers was an effective approach to more reliable detection of significant differences between the first and second testing periods.
\end{abstract}

Keywords: Quality of life, Blink, Uchida-Kraepelin psychodiagnostic test

\section{Introduction}

In a super-aged society [1], maintaining and improving the quality of life (QOL) of each individual is essential. QOL is defined not simply as being free of illness but also as experiencing life as completely physically, psychologically, and socially satisfactory [2]. Stress is known to negatively impact QOL, reducing motivation and causing a decline in physical condition up to and including illness. Therefore, measuring stress, understanding the stress state, and encouraging countermeasures can support the maintenance and improvement of and contribute to the early detection of declining health. There are various methods to measure stress including self-evaluation using a questionnaire, such as an SF-36 [3], and measurement of biological information based on salivary amylase [4]. The Uchida-Kraepelin psychodiagnostic test (usually used as a personality test) is known to reflect changes (such as a reduced motivation or poor physical conditions) in people caused by stress. Under stress-conditions such as exercise and drinking alcohol, the results obtained from testing subjects using the UchidaKraepelin psychodiagnostic test change [5]. In addition to the test, there are Minnesota Multiphasic Personality Inventory (MMPI) and Rorschach test [6] as a personality test. However, MMPI is a subjective evaluation of the subject, so it is difficult to reflect the unconscious mental and physical conditions. Rorschach test is complicated in the test and analysis. Drawbacks of the test include the timeestimating physical conditions using performance on the

\footnotetext{
† Corresponding: kageyama@ie.akita-u.ac.jp

$*$ a Akita University

1-1, Tegata Gakuen-machi, Akita-shi, Akita 010-8502, Japan
}

Uchida-Kraepelin psychodiagnostic test requires users to participate in the test for approximately 40 minutes-and the time required to explain the test to users prior to participation. Advantages include the fact that the test clarifies various relationships between the action of blinking and physical conditions; examples include indicating an increase in the blink rate when concentration decreases [7] and indicating an increased likelihood of blink bursts when the subject's arousal level decreases [8]. On the basis of these correlations, clarifying the relationship between the number of calculations performed on the Uchida-Kraepelin psychodiagnostic test and the number of blinks enables changes in physical conditions to be estimated from changes in the number of calculations estimated to occur during simple work on tasks other than the Uchida-Kraepelin psychodiagnostic test. This has various applications such as estimating a subject's physical condition using a simpler test than the Uchida-Kraepelin psychodiagnostic test, and using constant monitoring of the blinks of the person performing visual-display-terminals work to determine when to prompt them to take a break. Although the relationship between the Uchida-Kraepelin psychodiagnostic test and eye movements (including blinks) has been investigated [9], no literature indicating any studies directly investigating the relationship between the number of calculations and the number of blinks in the Uchida-Kraepelin psychodiagnostic test could be found. Therefore, in this study, we focus on blinking as a feature quantity, and examine the relationship between the number of blinks and the results of the UchidaKraepelin psychodiagnostic test. 


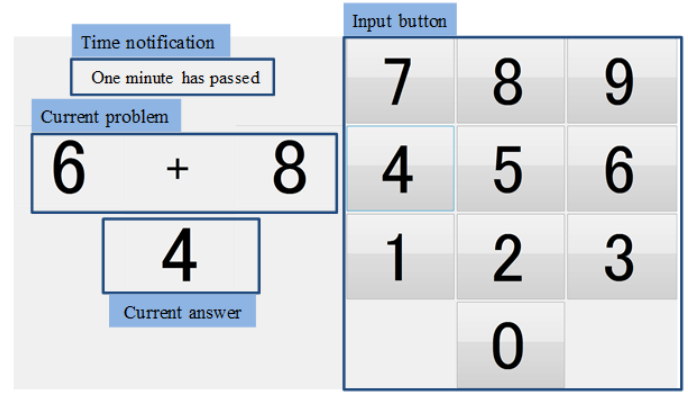

Figure 1: Example of program execution screen.

\section{Data Used}

2.1 Uchida-Kraepelin Psychodiagnostic Test In this test, participants are required to refer to a prepared number sequence and add the first two adjacent numbers. If the result is a single-digit number, they must write that number, whereas if it is a two-digit number, they must write only the last digit. This task is performed for 15 min continuously, followed by a $5 \mathrm{~min}$ rest, and then performed again for 15 min continuously, a total testing period of 35 minutes per test-day. The transition of the value, obtained by adding the number of calculations every minute, is used as a feature. To investigate blinking while the Uchida-Kraepelin psychodiagnostic test is taken, it is necessary to either obtain an image with a camera from diagonally below (which may stress the subject), or for the subject to wear an eyeglass-type device (also a potential stressor). In this study, to measure the number of blinks without stressing the subject, frontal facial image data was acquired while the subject was taking the Uchida-Kraepelin psychodiagnostic test on a personal computer (PC) and the number of blinks was calculated. Figure 1 shows an example of the program execution screen. The provision of answers and any corrections are submitted using a mouse, and moving to the next problem is performed using the keyboard. Answers corrected by the subjects were judged to be correct. The number of calculations was calculated using all calculations other than those judged to be incorrect by a subject.

2.2 Data Obtainment Experiment Five subjects participated in the experiments (denoted subjects A to E, all men in their twenties). Experiments for acquiring moving image data were conducted four times per person on four different days (although poor health necessitated subject D leaving the experiment on the third day). Photographing was performed using a web camera at an illumination of $3001 \mathrm{x}$ to 1,000 lx. The distance between the subject and the web camera was approximately $60 \mathrm{~cm}$. Figure 2 shows the experimental environment, and a flowchart of the experimental procedure is provided in Fig. 3. As previously stated, frontal facial imagery was collected while the subject was taking the Uchida-Kraepelin psychodiagnostic test on a PC. Furthermore, a questionnaire was administered before and after the experiment to record the subject's mental and physical conditions, establishing a baseline and then en-

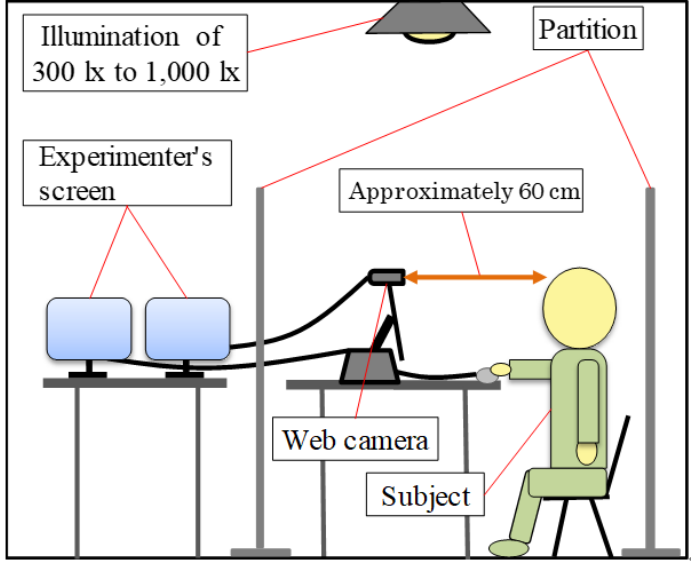

Figure 2: Experimental environment.

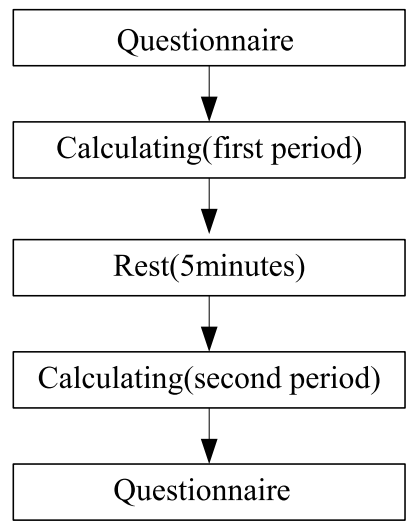

Figure 3: Procedural flowchart for data acquisition.

abling the calculation of differences. The data used in this study were acquired in accordance with the ethical regulations concerning studies involving humans at Akita University, Japan.

2.3 Questionnaire Whether a subject experiences stress during a task depends on their proficiency at the task, difficulties or challenges experienced in performing the task, and conditions at the time. Stress impacts work efficiency and calculation speed. Therefore, to enable the consideration of changes in achieved values for each subject, a questionnaire was administered to record each subject's mental and physical conditions before and after testing, and the stress experienced by each subject participating in the experiments was investigated. An extract from the questionnaire is provided in Table 1.

\section{Analytical Method}

3.1 Blink Frame Setting In this study, manual measurement of the number of blinks provided the basic data for analysis. The image data acquired through the experiment were visually confirmed frame by frame. Figure 4 shows an example of the process used to set the blink frame for each blink event. The frame showing a subject's eyes at their most closed point during a closing and opening cycle (one blink) was set as the blink frame for each blink. After manually recording blink frames, the number of blink 
Table 1: Questionnaire items.

\begin{tabular}{cl}
\hline & Feeling nauseous \\
& Dizzy \\
& Difficult to concentrate \\
& Tired/Feeling dull \\
& Sweating \\
physical conditions & Breathing disorder \\
& Feeling pulse fast \\
& Having a headache \\
& Having a sick(including a cold) \\
\hline \multirow{3}{*}{ Mental conditions } & Psychological burden in recent time \\
& Having nervous \\
& Having concerns \\
\hline \multirow{3}{*}{ Stress caused by } & Troublesome calculation \\
experiment & Troublesome PC operation \\
& Screen readability \\
& Streen caused by photography \\
\hline \multirow{3}{*}{ About the previous day } & Drinking on the previous day \\
& Working part-time on the previous day \\
& Bedtime and wake up time \\
\hline & Exercise habits \\
& Breakfast habits \\
Others & Vision correction(glasses,contact lenses) \\
\hline &
\end{tabular}

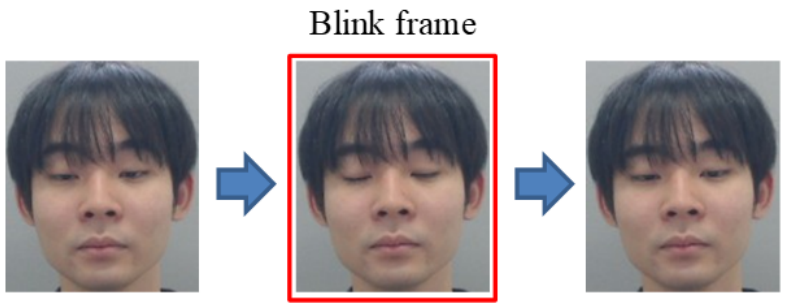

Figure 4: Example of blink frame setting.

frames per minute was calculated as the measured value of the number of blinks per minute.

3.2 Calculation of Correlation Coefficient Using the calculation answers recorded on the PC, the number of calculations per minute was determined. Figure 5 shows a transition example of the number of calculations and the number of blinks. Figure 6 shows a correlation diagram example of the number of calculations and the number of blinks. The correlation coefficient for the data was calculated assuming a negative correlation between the number of calculated answers and the number of blinks.

3.3 Late Increase Rate According to the UchidaKraepelin psychodiagnostic test, the late increase rate in the standard case tends to increase. However, if the subject finds it difficult to concentrate owing to their personality, or if the mental conditions or physical conditions at the time of the test are not appropriate, the late increase rate declines [10]. In this study, to investigate whether the same results can be obtained in the reproduction of the Uchida-Kraepelin psychodiagnostic test on a PC, the corresponding t-test [11] was applied to the number of calculations in the first and

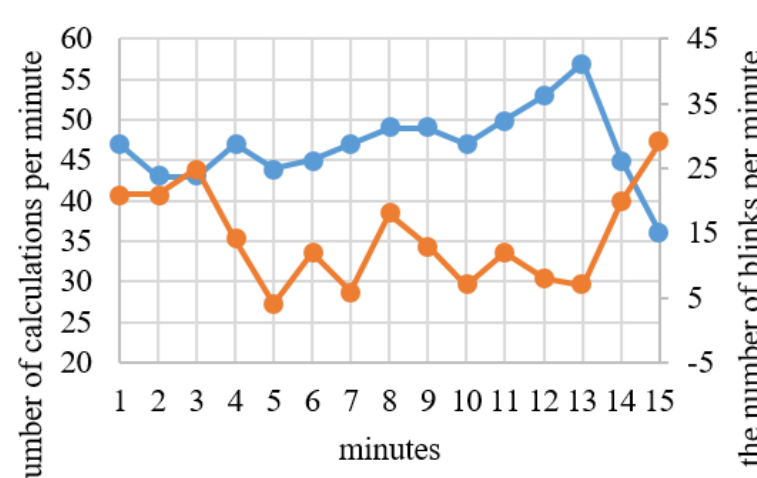

$\longrightarrow$ the number of calculations per minute — the number of blinks per minute

Figure 5: Transition example of the number of calculations and the number of blinks.(Subject B, Day 2, Second period).

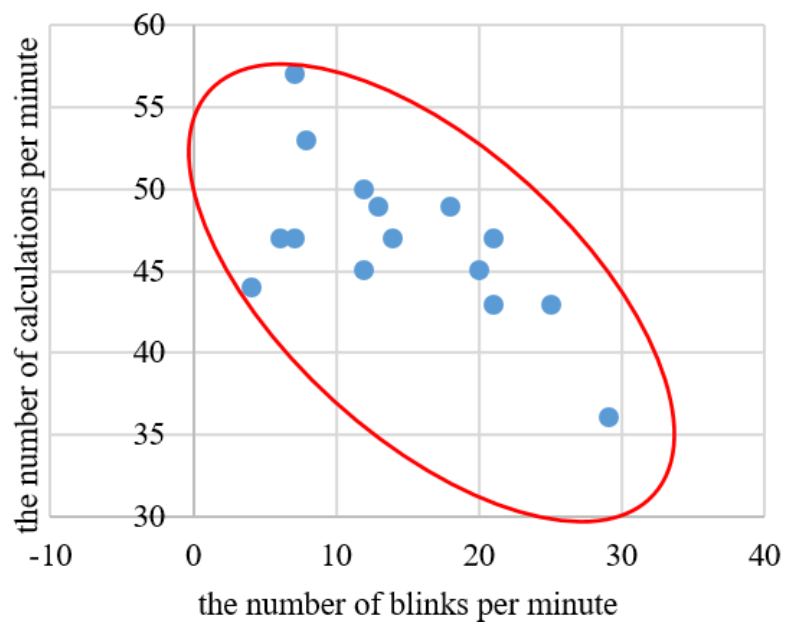

Figure 6: Correlation diagram example of the number of calculations and the number of blinks (Subject B, Day 2, Second period).

second periods, and the same examination was conducted to investigate whether the number of blinks differs between the first and second periods.

3.4 Examination Excluding Outliers The number of blinks and the number of calculations may have a large variance owing to the influence of some specific values. Therefore, the t-test was conducted again after excluding the outliers in the data. The outliers were set based on the quartile deviation. Sometimes, the number of elements in the first and second periods did not match owing to the exclusion of the outliers. Thus, Welch's test [11] was used.

\section{Results}

4.1 Correlation Coefficient Calculation Results Table 2 lists the correlation coefficients for the correlation between the number of calculations and the number of blinks. The correlation coefficient is approximately -0.40 or less, indicating negative correlation. The results suggest that it is possible to estimate the transition in the number of calculations by focusing on the transition in the number of blinks. 
Table 2: Correlation coefficient between the number of calculations and the number of blinks.

\begin{tabular}{lcccccc}
\hline & & \multicolumn{5}{c}{ Subject } \\
\cline { 3 - 7 } & & $\mathrm{A}$ & $\mathrm{B}$ & $\mathrm{C}$ & $\mathrm{D}$ & $\mathrm{E}$ \\
\hline \multirow{2}{*}{ Day 1 } & First & -0.52 & -0.06 & 0.44 & -0.55 & -0.27 \\
& Second & -0.37 & -0.16 & 0.24 & -0.42 & -0.39 \\
Day 2 & First & -0.57 & -0.47 & -0.08 & -0.43 & -0.47 \\
& Second & -0.65 & -0.63 & -0.48 & -0.35 & -0.63 \\
Day 3 & First & -0.77 & -0.47 & 0.09 & - & -0.51 \\
& Second & -0.47 & -0.44 & -0.40 & - & -0.61 \\
Day 4 & First & -0.70 & -0.55 & -0.19 & -0.49 & 0.15 \\
& Second & -0.70 & -0.53 & 0.15 & -0.04 & 0.19 \\
\hline
\end{tabular}

Table 3: Results of t-test on the number of calculations.

\begin{tabular}{cccccc}
\hline Subject & day & $\begin{array}{c}\text { First } \\
\text { ave. }\end{array}$ & $\begin{array}{c}\text { Second } \\
\text { ave. }\end{array}$ & Difference & p-value \\
\hline \multirow{3}{*}{ A } & 1 & 41.1 & 44.1 & -2.9 & 0.058 \\
& 2 & 42.1 & 44.1 & -2.1 & 0.228 \\
& 3 & 45.3 & 44.6 & 0.7 & 0.611 \\
& 4 & 44.5 & 45.1 & -0.6 & 0.698 \\
\hline \multirow{3}{*}{ B } & 1 & 43.3 & 47.7 & -4.3 & 0.021 \\
& 2 & 48.7 & 46.8 & 1.9 & 0.029 \\
& 3 & 48.1 & 50.7 & -2.7 & 0.098 \\
& 4 & 52.9 & 54.9 & -1.9 & 0.770 \\
\hline \multirow{3}{*}{ C } & 1 & 52.1 & 54.3 & -2.3 & 0.005 \\
& 2 & 51.3 & 53.0 & -1.7 & 0.190 \\
& 3 & 53.8 & 54.0 & -0.2 & 0.001 \\
& 4 & 53.3 & 56.1 & -2.7 & 0.056 \\
\hline \multirow{2}{*}{$\mathrm{D}$} & 1 & 49.0 & 50.0 & -1.0 & 0.377 \\
& 2 & 50.3 & 52.7 & -2.4 & 0.027 \\
& 3 & - & - & - & - \\
& 4 & 54.2 & 55.7 & -1.5 & 0.573 \\
\hline \multirow{2}{*}{ E } & 1 & 49.7 & 43.3 & 6.4 & 1.000 \\
& 2 & 51.0 & 50.3 & 0.7 & 0.001 \\
& 3 & 48.7 & 48.7 & 0.0 & 0.160 \\
& 4 & 54.3 & 55.3 & -1.1 & 0.019 \\
\hline
\end{tabular}

4.2 Results of Late Increase Rate Table 3 lists the results of a t-test on the number of calculations. Table 4 lists the results of a t-test on the number of blinks. A significant difference was observed in seven data points in the number of calculations and two data points in the number of blinks. The results suggest that the late increase rate in the UchidaKraepelin psychodiagnostic test is also reflected in the test on the PC. In addition, there is a peculiar change in the late increase rate in the number of blinks.

4.3 Results of Examination Excluding Outliers Table 5 shows the results of Welch's test on the number of calculations after excluding outliers. Table 6 lists the results of Welch's test on the number of blinks after excluding outliers. A significant difference was observed in nine data points in the number of calculations and five data points in the number of blinks. From the results, it can be seen that it is useful to exclude outliers when calculating the late in-
Table 4: Results of t-test on the number of blinks.

\begin{tabular}{cccccc}
\hline Subject & day & $\begin{array}{c}\text { First } \\
\text { ave. }\end{array}$ & $\begin{array}{c}\text { Second } \\
\text { ave. }\end{array}$ & Difference & p-value \\
\hline \multirow{3}{*}{ A } & 1 & 7.1 & 7.1 & 0.1 & 0.945 \\
& 2 & 8.2 & 8.3 & -0.1 & 0.962 \\
& 3 & 6.7 & 7.7 & -1.1 & 0.100 \\
& 4 & 8.7 & 7.4 & 1.3 & 0.236 \\
\hline \multirow{3}{*}{ B } & 1 & 23.7 & 19.2 & 4.5 & 0.347 \\
& 2 & 11.1 & 14.5 & -3.4 & 0.060 \\
& 3 & 17.6 & 14.3 & 3.3 & 0.833 \\
& 4 & 18.4 & 18.7 & -0.3 & 0.031 \\
\hline & 1 & 7.2 & 5.4 & 1.8 & 0.810 \\
& 2 & 7.7 & 7.4 & 0.3 & 0.090 \\
& 3 & 10.1 & 7.2 & 2.9 & 0.001 \\
& 4 & 8.5 & 8.3 & 0.3 & 0.317 \\
\hline \multirow{3}{*}{$\mathrm{D}$} & 1 & 2.4 & 2.9 & -0.5 & 0.390 \\
& 2 & 3.0 & 2.2 & 0.8 & 0.171 \\
& 3 & - & - & - & - \\
& 4 & 2.9 & 2.1 & 0.8 & 0.705 \\
\hline \multirow{3}{*}{ E } & 1 & 8.2 & 26.9 & -18.7 & 0.387 \\
& 2 & 9.5 & 8.7 & 0.7 & 0.133 \\
& 3 & 15.8 & 12.7 & 3.1 & 0.145 \\
& 4 & 22.7 & 21.3 & 1.3 & 0.963 \\
\hline
\end{tabular}

Table 5: Results of Welch's test on the number of calculations after excluding outliers.

\begin{tabular}{cccccc}
\hline Subject & day & $\begin{array}{c}\text { First } \\
\text { ave. }\end{array}$ & $\begin{array}{c}\text { Second } \\
\text { ave. }\end{array}$ & Difference & p-value \\
\hline \multirow{4}{*}{ A } & 1 & 42.0 & 43.3 & -1.3 & 0.261 \\
& 2 & 42.5 & 42.5 & -0.1 & 0.932 \\
& 3 & 43.6 & 44.6 & -1.0 & 0.324 \\
& 4 & 44.5 & 44.8 & -0.3 & 0.840 \\
\hline \multirow{3}{*}{ B } & 1 & 42.9 & 48.3 & -5.4 & 0.001 \\
& 2 & 48.7 & 46.3 & 2.4 & 0.036 \\
& 3 & 48.1 & 50.7 & -2.7 & 0.016 \\
& 4 & 53.8 & 54.8 & -1.0 & 0.154 \\
\hline & 1 & 51.8 & 55.0 & -3.3 & 0.001 \\
C & 2 & 51.6 & 53.1 & -1.5 & 0.023 \\
& 3 & 53.8 & 54.1 & -0.3 & 0.600 \\
& 4 & 53.8 & 55.5 & -1.8 & 0.003 \\
\hline \multirow{3}{*}{$\mathrm{D}$} & 1 & 46.8 & 48.5 & -1.7 & 0.017 \\
& 2 & 50.5 & 52.0 & -1.5 & 0.084 \\
& 3 & - & - & - & - \\
& 4 & 53.8 & 55.3 & -1.5 & 0.055 \\
\hline \multirow{3}{*}{ E } & 1 & 49.2 & 43.3 & 5.9 & 0.001 \\
& 2 & 51.5 & 50.6 & 0.9 & 0.122 \\
& 3 & 48.7 & 47.6 & 1.1 & 0.285 \\
& 4 & 54.3 & 55.8 & -1.5 & 0.030 \\
\hline
\end{tabular}

crease rate using the number of calculations and the number of blinks.

\section{Discussion}

The number of calculations and the number of blinks generally tended to show a negative correlation, but weak corre- 
Table 6: Results of Welch's test on the number of blinks after excluding outliers.

\begin{tabular}{cccccc}
\hline Subject & day & $\begin{array}{c}\text { First } \\
\text { ave. }\end{array}$ & $\begin{array}{c}\text { Second } \\
\text { ave. }\end{array}$ & Difference & p-value \\
\hline \multirow{3}{*}{ A } & 1 & 6.5 & 6.7 & -0.2 & 0.769 \\
& 2 & 7.5 & 8.3 & -0.8 & 0.370 \\
& 3 & 6.7 & 6.4 & 0.4 & 0.508 \\
& 4 & 7.6 & 6.7 & 0.9 & 0.268 \\
\hline & 1 & 20.8 & 17.1 & 3.7 & 0.037 \\
B & 2 & 8.3 & 12.5 & -4.2 & 0.042 \\
& 3 & 12.2 & 14.3 & -2.1 & 0.389 \\
& 4 & 12.3 & 11.6 & 0.7 & 0.822 \\
\hline & 1 & 6.9 & 5.4 & 1.5 & 0.124 \\
C & 2 & 6.9 & 6.8 & 0.2 & 0.834 \\
& 3 & 8.6 & 6.4 & 2.2 & 0.011 \\
& 4 & 7.9 & 6.0 & 1.9 & 0.055 \\
\hline & 1 & 2.0 & 2.6 & -0.6 & 0.083 \\
D & 2 & 2.5 & 1.7 & 0.8 & 0.085 \\
& 3 & - & - & - & - \\
& 4 & 2.8 & 1.6 & 1.2 & 0.002 \\
\hline \multirow{3}{*}{ E } & 1 & 7.7 & 28.5 & -20.8 & 0.001 \\
& 2 & 7.4 & 5.7 & 1.7 & 0.119 \\
& 3 & 10.9 & 11.7 & -0.8 & 0.586 \\
& 4 & 22.1 & 20.8 & 1.3 & 0.331 \\
\hline
\end{tabular}

lation, no correlation, and positive correlation were also obtained. In particular, the latter tendencies were frequently observed in the first-day data. In data acquisition experiments the subjects encounter a variety of unfamiliar elements such as the operational environment, learning the task, and whatever problems they might encounter. In addition, calculation proficiency increases with practice, and thus the number of calculations a subject can perform in the given time increases significantly [5] [12]. This accounts for the tendency for data gathered on the first day of the experiment to differ from that gathered over the rest of the experimental period.

\section{Conclusion}

This study aimed to develop a method to estimate a subject's physical conditions or know when to prompt them to take a break, using a simple test based on recording how often a subject blinks when performing the Uchida-Kraepelin psychodiagnostic test on a PC and correlating this number with their performance results. The relationship between these results was examined and a negative correlation was identified. Moreover, there was an indication of a correlation between late increase rate specific to the Uchida-Kraepelin psychodiagnostic test and the chosen test method of using a PC. Furthermore, the average values of not only the number of calculations but also the number of blinks appeared to differ significantly between the first and second periods, indicating the possibility of a distinctive feature such as the late increase rate.

In future work, we plan to construct a system to automatically measure the frequency of blinks increasing the efficiency of the experiment and laying the groundwork for further investigation.

\section{Acknowledgment}

This study was supported by JSPS KAKENHI Grant Number JP19K12909.

\section{References}

[1] Special issue: How to bring energy and growth to Japan by strategic use of smart ICT, Ministry of Internal Affairs and Communications http: //www. soumu.go.jp/johotsusintokei/whitepaper/ $\mathrm{ja} / \mathrm{h} 25 / \mathrm{html} / \mathrm{nc} 123110$.html, access date: 2020.1 .

[2] Y. Doi, "Introduction-Conceptual Issues on Quality of Life (QOL) and Importance of QOL", Research Journal of the National Institute of Public Health, Vol.53, No.3, pp.176180, 2004.

[3] S. Fukuhara, J. E. Ware Jr., M. Kosinski, S. Wada and B. Gandek, "Psychometric and Clinical Tests of Validity of the Japanese SF-36 Health Survey", Journal of Clinical Epidemiology, Vol.51, No.11, pp.1045-1053, 1998. DOI: 10.1016/S0895-4356(98)00096-1

[4] H. Haginoya and Y. Saeki, "The Usefulness of Salivary $\alpha$ Amylase Activity to Evaluate Degree of Stress", Japanese Journal of Nursing Art and Science, Vol.10, No.3, pp.19-28, 2012.

[5] J. Kurokawa, "Evaluation by Repeated Use of UchidaKraepelin Psychodiagnostic Test (1st Report): Evaluation of Various Conditions by Daily Use of the Test", Japanese journal of occupational medicine and traumatology, Vol.60, No.2, pp.74-90, 2012.

[6] C. Fukatsu, "Psychological tests for psychiatric care", Psychiatria et neurologia Japonica, Vol.109, No.3, pp.282-287, 2007.

[7] F. Yamada, "Evaluation of Psychological Stress and its Management (< Special Feature> Fatigue and Stress)", Society of Biomechanisms Japan, Vol.21, No.2, pp.69-74, 1997.

[8] R. Hosaka and A. Watanabe, "An Approach to the Evaluation of Arousal Level by Blinking Interval Analysis", Japan Ergonomics Society, Vol.19, No.3, pp.161-167, 1983. DOI: $10.5100 / \mathrm{jje} .19 .161$

[9] H. Kawaguchi, "Investigation of the Relationship between Attention and Blocking Phenomena during UchidaKraepelin Test", The Visualization Society of Japan, Vol.34, No.133, pp.8-13, 2014. DOI: 10.3154/jvs.34.8

[10] T. Bookstore Editorial Department, "Job Aptitude Test Uchida-Kraepelin Psychodiagnostic Test Complete Understanding Manual", Tokyo, Japan, Tsuchiya Bookstore Corporation, 2008.

[11] S. Kurihara, "Introductory statistics from testing to multivariate analysis design", Tokyo, Japan, Ohmsha, 2011.

[12] Y. Fukuda and R. Sakai, "A Method of Work Appraisement by Professing Equation in Production", Journal of Japan 
Industrial Management Association, Vol.32, No.3, pp.188-

194, 1981.

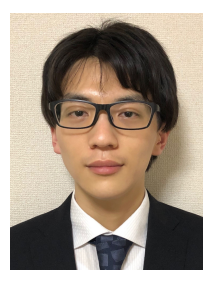

Shunsuke Nakano (Non-member) received B.E. and M.E. degrees in computer science and engineering from Akita University, Japan, in 2018 and 2020 respectively, and then joined CNS Co., Ltd. His research interests include human sensing.

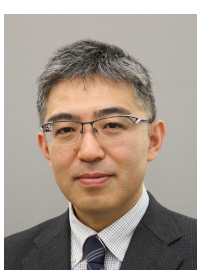

Yoichi Kageyama (Member) received the B.E. and M.E. degrees in computer science and engineering and the Dr. E. degree from Akita University, Japan, in 1995, 1997, and 2001 respectively. He joined Akita University as a Research Associate in 1997, became an Assistant Professor in 2001, and an Associate Professor in 2004. He is now a Professor with the Department of Mathematical Science and Electrical-Electronic-Computer Engineering, Graduate School of Engineering Science. His research interests include remote sensing, human sensing, image processing, and image recognition. 